\title{
Adolescent Deviation and Age
}

\author{
Jeanette Covington ${ }^{1}$
}

Received June 30, 1982

Traditional theories of delinquency causation generally fail to consider delinquency in the context of norms and age-role transitions peculiar to adolescence. Hence, in this study, an age-based theory of delinquency causation is developed, which assumes the importance of norms and roles specific to adolescence. This theory draws upon the assumption that socialization is recurrent, in contrast to the premises regarding socialization which underlie traditional theories of adolescent deviance. The recurrent model of socialization and that assumed by traditional theorists are discussed, and their implications for the causes of delinquent behavior are examined. Some effort is made to show that the recurrent model of socialization suggests an anomie of age as the basis for delinquent acts. It is suggested that this age-based anomie stems from conditions of normlessness associated with certain role transitions in adolescence and the pacing of these transitions. Further, it is suggested that certain groups are especially prone to an anomic age transition. The role transitions most likely to be subject to such anomic conditions and the adolescent subgroups most prone to experience anomie as a result of the pacing of their age-role transitions are identified.

\section{INTRODUCTION}

The causes of delinquency have concerned a number of sociologists, and many of their explanations have required adolescent alienation from prior norms and values and subsequent socialization into a delinquent

\footnotetext{
'Assistant Professor, Department of Sociology, University of Michigan, Ann Arbor, Michigan 48109. Received her Ph.D. from the University of Chicago in 1979. Major interests are deviant behavior, drugs, juvenile delinquency.
} 
subculture. The basis for the break with prior moral norms prohibiting deviant behavior is often thought to stem from a frustration arising from failed attempts to achieve values learned in childhood. Such explanations require a childhood socialization process that exerts enormous influence over the juvenile, regardless of the relevance of such values to later adolescent roles and leisure pastimes. In this study, an effort is made to examine these assumptions about the influence of childhood socialization and its import in encouraging adolescent frustration and deviant behavior. It is suggested that socialization might better be regarded as recurrent, rather than as a single process occurring in childhood; the causes of delinquent behavior are then identified in terms of this alternate model of socialization.

In the first section, the assumptions of traditional delinquency theorists - specifically strain theorists-regarding childhood socialization are examined for their implications for strain explanations of delinquency causation. It is suggested that these explanations of delinquency require a childhood socialization process in which certain economic/achievement values are internalized and thereby made capable of generating frustration in adolescence. This notion regarding the long-term effects of values learned in childhood is questioned because of the limited relevance of such values for an age grade composed of dependent consumers. Such economic/achievement values may have relevance primarily for older adolescents; therefore, these values ability to generate frustration and alienation and encourage deviant behavior might best be applied to older juveniles. However, for younger juveniles, the causes of delinquency may lie in the very absence of norms to guide their transition from adolescence to adulthood. This hypothesis assumes that a break with values learned in childhood occurs solely as a result of age-related role transitions that render such values irrelevant. In this view, socialization is recurrent and subject to recur with each transition in age-related roles. In the second section, the assumptions underlying recurrent socialization are briefly identified; and in the third section, the implications of this alternate model of socialization for delinquency theories are discussed. An effort is made to identify points at which socialization, which recurs in adolescence, is likely to fail to provide relevant norms and values for this age transition. This normlessness or anomie of age is further discussed in the fourth section, with an eye to explaining certain fairly common forms of delinquency in these terms.

\section{TRADITIONAL DELINQUENCY THEORIES: ASSUMPTIONS REGARDING SOCIALIZATION}

Sociologists have long relied upon delinquent subcultures as a basis for their explanations of adolescent deviation. Generally, sociologists 
contend that (re)socialization and assimilation of subcultural values cause delinquent behavior to be regarded as prestigious and thus allow the juvenile to break with moral norms and values generally prescribed by the larger society. Given this emphasis on subcultures as the basis for delinquent acts, it has been necessary to identify conditions thought sufficient to cause the juvenile to break with traditional values and pursue deviant values within the context of a subculture. Several strain theorists have described a catalyst seemingly sufficient to explain this break with norms and thereby the origins of delinquent subcultures as the basis for delinquent acts (Cloward and Ohlin, 1960; Cohen, 1955; Merton, 1957).

The catalyst thought to incur this break stems from socially induced conditions of frustration which involve the failure to achieve specific economic/achievement ends. Certain subgroups-notably lower class juveniles - are particularly likely to be frustrated in their efforts to achieve these ends because of the maldistribution of legitimate means; in their frustration, these groups are thought to resort to illegitimate or deviant means. Society then loses its ability to regulate the mechanisms by which culturally prescribed ends will be achieved for these groups; thus, any set of means - even those normatively proscribed - come to be regarded as tenable to achieve desired ends. This state of anomie, or normlessness, encourages delinquent behavior.

This explanation of socially induced strain as a catalyst for delinquent behavior and subcultural formation rests upon fairly traditional assumptions regarding the nature of socialization, namely, those which emphasize the importance of values and norms internalized in childhood. Strain theorists proceed as if both moral norms and cultural goals are internalized during childhood socialization, when the vulnerable child, desirous of adult approval and given to identification with and imitation of parents, is thought to learn parental values.

With childhood interiorization of moral norms, a set of internal controls is established and the single-minded self-interested amorality of original man is reversed. When thus made moral by this process, man is assumed thereafter to experience feelings of guilt and shame from involvement in immoral behavior.

Similarly, man is thought to internalize certain concepts of self-worth, since strain theorists believe that cultural goals are exalted to the level of ideals during childhood and hence made capable of confirming or denying worth. Achievement of these goals is presumed to provide man with a design for living. This has come to mean that man directs himself toward attainment of symbols such as wealth, power, and prestige, which when obtained bestow a sense of accomplishment.

To suggest that values and norms are internalized during childhood is to imply that they can permanently direct behavior. That is, when these economic/achievement ends are obtained, they are capable of generating 
feelings of worth long after they have been learned in childhood. Conformity to internalized moral norms also bestows a sense of righteousness. By contrast, failure to achieve status ends or violation of moral norms causes the individual to experience feelings of shame and frustration. With the establishment of intrapsychic controls, implied in the concept of internalization, the socialized individual is forever forced to evaluate him/herself and his/her behavior in these terms.

Strain theorists also assume that these cultural goals take precedence over moral norms in an achievement-oriented, materialistic American society; hence, a certain value hierarchy is likewise assimilated in childhood (Clinard, 1964). Strain theorists then proceed as if the fully socialized individual willingly violates moral norms in an effort to achieve cultural goals (Merton, 1957; Cloward and Ohlin 1960). The frustration generated by the failure to achieve internalized values is thus presumed sufficient to cause the violation of internalized norms.

The effects of such frustration can be even more devastating. For example, it has been suggested that the sense of guilt attendant upon the failure to achieve these ends is sufficient to force the juvenile to establish a set of intrapsychic defenses that allow him/her to repress these feelings of self-doubt and shame (Cohen, 1955). The negativistic deviant behavior in which he/she involves him/herself is then understood as a form of reaction formation, which is especially effective in shielding him/her from any anxiety caused by these repressed values. In this fashion, the juvenile grapples with the effects of previously internalized values that persist in the unconscious and constantly threaten to surface.

With the concept of internalization, values acquired in childhood are virtually elevated to the level of instincts, so that violation of them necessarily generates feelings of frustration and shame, regardless of the social context and situation in which the individual finds him/herself. These values' constant demand for satisfaction and their priority over other motivational forces give behavior consistent with them a certain urgency-an urgency sufficient to compel initiation and cessation of behavior and delinquent subcultural formation. For strain theorists, man is never freed from the internalized drive to achieve, and efforts to repress this drive only arouse tension and anxiety. Indeed, because these values are not subject to elimination, the individual is forced to seek alternate and often deviant paths in order to satisfy them. Internalization, then, permanently binds the individual to values learned in childhood.

It is possible, however, to conceive of childhood socialization and the effects of internalization in an entirely different fashion. To begin with, socialization, and thus value assimilation, may well occur throughout the life cycle (Gordon, 1976; Kohlberg and Gilligan, 1971; Maccoby, 1968). 
This recurrent socialization is necessary because values learned in childhood, and indeed values learned at each stage of the life cycle, can somehow be irrelevant for later stages. This limited value relevance and assured value obsolescence guarantee some socialization after childhood. The discarding of prior values and the learning of new ones is, in this view, seen as a transition to be expected. Values and norms learned in childhood are no longer seen as so exalted and capable of constantly frustrating the individual.

Childhood socialization may not be sufficient to bestow the presumed urgency upon values. Values may have such priority only when they are somehow relevant to roles and social contexts. However, because roles and contexts are subject to change throughout the life cycle, it would seem that values able to frustrate and confirm worth would be subject to change. Thus, only values learned in childhood which are sufficiently generalizable to later roles and social contexts can be assumed to have the persisting motivational impact traditionally assigned to them.

It is doubtful that cultural goals described by strain theorists as transmitted by parents in childhood will be seen as compelling in all later contexts. The concept of internalization may have been mistakenly applied to these values, since they are not sufficiently generalizable to be continuously relevant. The capacity of such values to inspire commitment would seem to depend upon their ability to confirm one's worth relative to peers, provide access to real rather than anticipated rewards, and provide a set of goals to serve as the ends of action (Kornhauser, 1978; Sapir, 1958). Yet it seems unlikely that pursuit of cultural goals such as power, wealth, and prestige would provide adolescents with an all-encompassing design for living. Rather, these values might seem compelling primarily to adults. In short, adults and adolescents might be regarded as two distinct age strata or functionally differentiated groups of producers and consumers. Two such distinct strata would seemingly have different values and thereby pursue different goals.

There can be no doubt that the economic/achievement goals discussed by strain theorists are of central relevance to adults involved in producer roles, for these adults' lives usually revolve around a work environment in which such values provide a design for living. Work-related occupational identities are one of the most crucial bases for self-definition among producers in terms of confirming moral worth or assessing one's accomplishments relative to peers (e.g., co-workers, neighbors). The inability to achieve these goals, then, is especially likely to generate a sense of frustration in this group.

The occupational socialization that occurs with the assumption of producer roles may also serve to strengthen commitment to these values, for 
the assumption of such roles forces the ego to grapple with problems that require discipline and denial. To the extent that such discipline and sacrifice lead to success, the accompanying rewards (ends of action) may be endowed with the ability to gratify. If these strivings are attached to real rewards, the achievement standards that encourage such behavior may ultimately be elevated to the level of values with the power to confirm or deny worth.

Yet such economic/achievement values may have little relevance for the leisure environments of adolescence. There may be some question whether economic/achievement goals could be so exalted in a leisure class of consumers, for whom the sacrifice and discipline of achievement would be associated with mere anticipation of rewards, rather than attainment. It also seems unlikely that these ends could assume such importance, since their attainment in adolescence would require achievement in the context of a pupil role and such achievement (equated with language and clerical precision and behavior such as the passive receiving and repeating of facts) is not widely regarded as compelling for adolescents (Sexton, 1969; Csikszentmihalyi and Larson, 1978).

We are thus cautioned toward only a qualified acceptance of strain theories, for such explanations may apply only to older adolescents who have actually entered producer roles or for whom such entry is imminent. Indeed, Lerman (1968) found that conforming to deviant subcultural values was rated more highly among younger adolescents than doing well on a job. However, this hierarchy shifted for older boys, so that job success increased in value and became more important to them than conformity to the deviant subculture. Furthermore, many of the older adolescents who were highly supportive of deviant values two years prior to the study had by the time of the study shifted their emphasis to job success. This seems to suggest that the economic/achievement values described by strain theorists are crucial, but perhaps primarily for older adolescents who are on the verge of initiating employment.

However, to understand the deviance of younger adolescents involved in leisure-oriented life-styles, another set of assumptions regarding the origins of values that guide action seems to be in order. Specifically, one might consider these youths' acquisition of values in the context of a socialization process that requires a recurring revision of values consistent with changes in age-related roles, rather than in terms of the continued importance of parentally sponsored values acquired in childhood.

\section{RECURRENT SOCIALIZATION}

The assumption that socialization is recurrent stems from the notion that values learned earlier in the life cycle are replaced with new values as 
changes in roles occur with age transitions. These role changes are likely to affect members of a single age group simultaneously, and this has caused many social scientists to conceive of various age groups as separate age strata (Benedict, 1938; Clausen, 1968; Foner and Kertzer, 1978; Gordon, 1976; Maccoby, 1968). For example, members of a single age stratum experience major events and life transitions at approximately the same time (e.g., birth, marriage, death) and their common experience of similar events distinguishes them as a group. Moreover, certain roles are appropriate to an age group, for example, those defined by law or those less formally imposed. (Certainly child labor laws have assured the functional differentiation of age groups, so that one stratum assumes producer roles and the other is confined to consumer roles.) This common experience of major life events and incumbency in similar age-appropriate roles is believed to be sufficient to assure the development of values or value configurations specific to a single age group.

Furthermore, the values of an age group or cohort may be affected by specific social or historical changes (Ryder, 1965; Eisenstadt, 1956). For example, major economic shifts (such as depression or affluence) or wars may radically alter the norms of a particular cohort. Hence, a cohort reaching maturity or young adulthood in time of war may have values quite different from a cohort that reaches maturity in peacetime. The former cohort might be expected to place greater emphasis on values such as patriotism, loyalty, and heroism than a cohort of similar age in peacetime conditions. Hence, social change may radically alter intercohort or intergenerational transmission of values or norms, such as the transfer that occurs with childhood socialization. Thus, adolescents could easily be seen to adhere to values quite different from their parents.

Values do not merely stem from intergenerational transmission, but arise from the common experiences and roles specific to a certain age group. The catalyst for value change lies within the process of aging, for as the agebased roles that generate values change, so too do the values. In understanding value change, it becomes necessary to identify conditions that retarded or accelerate the aging process.

One suggestion has been that the aging process may be accelerated largely because of occupational roles defined by class. For example, one study indicated that males of lower and working class backgrounds perceived themselves as reaching middle age and old age earlier than their middle class counterparts (Neugarten and Peterson, 1957). Presumably, the former group's aging process was accelerated by their employment in manual occupations, in which their careers as producers were likely to be considerably shorter than those of their middle-class counterparts in sedentary white-collar professions. Hence, the former group anticipated the assumption of the dependent consumer roles associated with the aged at an 
earlier age, and their identification of themselves as mature or middle aged predated that of their middle class counterparts. Class-linked occupational demands seem to have enormous implications for self-perceptions of aging. This suggests that the time schedule for age-related role transitions may be problematic. After all, no distinct age nor specific set of norms may define the manner in which age transitions appropriately occur.

\section{RECURRENT SOCIALIZATION: IMPLICATIONS FOR DEVIANCE THEORY}

If we take the view that socialization is recurrent, it becomes possible to examine the causes of delinquent behavior in slightly different fashion. Rather than assuming that adolescent deviation represents a frustrated reaction to failed efforts at achieving values acquired in childhood, we may explain delinquency in terms of a break with parentally sponsored values and a substitution of new age-based values that come about merely as an adaptation to age-related role change or even social change. Yet, in general, sociologists of deviance have ignored the capacity of role change or social change to encourage delinquent subcultural formation. There has been one notable exception.

Simon and Gagnon (1976) analyzed deviant behavior in terms of such assumptions, particularly those regarding the influence of social change, when they examined the offenses of affluent youth in the 1960s. They suggested that the values and value hierarchies of these young adults, forced to adapt to social change, changed from those provided by parents. The cohort raised during the Depression years was inclined to emphasize such values as thrift, denial, discipline, and security. And the rewards that stemmed from such efforts were experienced as gratifying. By contrast, their offspring, raised in a period of prosperity, did not share this emphasis on thrift and discipline. And because the children enjoyed the rewards of such efforts without any effort themselves, the rewards ultimately ceased to be gratifying. Society lost its ability to regulate the behavior of these middle class youth (anomie of affluence), since it could no longer direct them toward goals that satisfied them. This situation led to a search for individually defined (as opposed to collectively defined) forms of gratification in the 1960s youth cohort. Not surprisingly, these individually defined forms of gratification were frequently deviant (e.g., drugs, drifting).

We need not confine ourselves to adolescent deviation in the sixties, for if we assume that socialization is recurrent, we may easily conclude that the catalyst for delinquent subcultural formation (even in the absence of social change) lies in the orderly transition of age grades. In adolescence, 
juveniles may begin to question the relevance of parentally sponsored norms and values for their daily experiences. Further more, peers with common social experiences and roles may assume a crucial role in socializing the adolescent as their ability to confirm worth in leisure roles is greatly enhanced.

This value change, which occurs with age, is frequently problematic, as few norms exist to govern many age transitions and this may be especially true of the transition from adolescence to adulthood. In the absence of norms to govern this particular transition, society loses its capacity to regulate the behavior of adolescents and a period of anomie - an anomie of age-ensues.

Parents cease to wholly control the behavior of adolescents; parents are unable to provide them with norms or values which are sufficiently relevant to confer feelings of worth upon them or goals whose accomplishment proves gratifying to adolescents. Further, parent/adolescent conflict is common largely because adults may be inclined to resist and attempt to slow this transition. In part, this anomie of age is also based upon the absence of norms to govern the pacing of this age transition.

In discussing the implications of the anomie of age for delinquency causation, we must identify the specific age-role transitions for which the problem of normlessness is greatest. Also, because the anomie of age is in part a normlessness that stems from the pacing of this transition, it may be useful to determine the conditions thought to accelerate or retard adolescent entry into adult roles. Identification of the bases for entry into adulthood may say much about conditions that affect adolescents' perceptions of their adultness. It may also allow for the identification of subgroups most likely to experience the anomic conditions associated with this age transition and thereby suggest which juvenile subgroups are especially prone to delinquent behavior or labeling by adults.

\section{ANOMIE OF AGE}

The roles most likely to be characterized by anomic transitions are those with the greatest discontinuity between their childhood and adult manifestations. We might argue that discontinuity between childhood and adult roles is greatest in the areas of sexual identity, drug use, and autonomy. For sexual identity, it has been suggested that the sexless child must be transformed into the sexually normal adult (Benedict, 1938). The child taught to regard sex as sinful must reverse previous conceptions and regard sex as normal behavior. Similarly, the drug-abstinent child must feel compelled to experiment with drugs in a manner similar to adults; and the 
passive child must be transformed into the dominant, self-determining adult. These transitions typically occur during adolescence, when childhood roles and values become obsolete and new values and new designs for living are developed to replace them. At this point, adult statuses are not ascribed, but must be achieved.

\section{Sexual Identity}

With the development of a sexual identity, the crucial interactants are often opposite-sex peers, who define acceptable standards for interaction because of their enhanced power to demand conformity and provide approval (Kanin, 1967; Teevan, 1972; Hornick, 1978). These peers acquire this power to socialize or to force ego to grapple with new problems and alter previously held values simply because they alone are capable of confirming worth in terms of sexual attractiveness. Similarly, same-sex peers acquire the potential to socialize, since they offer suggestions about reasonable adaptations to these new challenges and demands. Their advice is likely to seem especially relevant because of their own exposure to similar problems and their seeming expertise in making "legitimate" adaptations.

In fact, there seems to be virtually no basis for value continuity from childhood to adulthood, not only because of the irrelevance of previous values and roles but also because parents often appear to be slow in recognizing the need for this transition, at least from the adolescent's standpoint. This means that parent/child dialogue on matters of sex is likely to be especially limited, so that parents are not given an opportunity to revise their views and present what might seem to be a more reasonable position, even if they could (Dickinson, 1978). Hence, the process of unlearning and discarding prior values and developing replacement values may proceed with minimal parental input.

\section{Drugs}

Similarly, with the social use of drugs, parental demands for total abstinence in childhood are notably discontinuous with adult drug use patterns. Yet it is a widely known fact that attempts to make this transition (defined as status crimes) are often initiated in adolescence. At this point, parental demands may seem especially rigid and unworkable in the face of competing demands from peers. And parent/child dialogue is likely to be limited here as well, so that parents are not given an opportunity to revise demands and offer advice on reasonable adaptations. In short, parental influence over adolescent drug use is likely to be limited. 
Certainly, several studies suggest that parental influence affects adolescent drug use (Cahalan et al., 1969; Bacon and Jones, 1968; Cahalan and Room, 1974; Smart and Fejer, 1972). However, these studies fail to examine drug behaviors over time and are unable to distinguish between parental influence upon initial adolescent drug behaviors (Kandel et al., 1978). In Kandel et al.'s study, parental influences were found to be a poorer predictor of hard liquor or marihuana use than peer influence. Only with illicit drugs other than marihuana (primarily amphetamines or barbituates) was parental influence seemingly a better predictor of initial drug use than peer influence.

However, parental attitudes or permissivness were not crucial; rather, parental use of psychoactive substances was related to adolescent illicit drug use. It seems, then, that adolescent imitation of parental coping styles or adaptations to stress may be related to use of illicit substances, rather than assimilation of parental values or response to parental attitudes encouraging or discouraging such use. Further, the substances used by adolescents are often different from those used by parents; and there may be a more explicit orientation toward achievement of euphoria among adolescents, rather than a medical orientation such as that found among parents.

In short, parents may have little direct impact on adolescent initiation of drug use, since parents continue to disapprove "illicit" use of licit drugs. Adolescent use of drugs may then assume unique forms quite different from those employed by parents - for example, intravenous use, "spree shooting" (Carey and Mandel, 1968; Davis and Munoz, 1968). At best, parents exert only an indirect influence through their own psychoactive and hard liquor use, which may serve to encourage adolescent initiation and experimentation even while parental disapproval of adolescent drug use serves to limit parental ability to socialize or directly affect the nature of adolescent drug behavior.

\section{Autonomy}

Finally, the discontinuities between child and adult in terms of autonomy and self-determination require a transition from one role to another entirely opposite in character. Again, it becomes necessary to unlearn or discard previous values and roles which require unconditional obedience to adult dictates. Yet parents and teachers may again be ill equipped to aid in this transition because it forces them to relinquish their power to control and discipline the adolescent.

Parents are particularly limited in terms of explaining how the adolescent is to grapple with this increasing autonomy. On the one hand, 
they encourage independence, since they are aware of its relevance for forthcoming producer roles. Yet they feel such assertions of autonomy should be confined to certain circumstances and not directed at them or other adults. Their demands for obedience to their dictates are often absolute, and hence parents are unable to judge when the adolescent feels his/her autonomy has been violated. Similarly, teachers demand politeness and obedience in their charges and are likely to regard assertions of autonomy as defiance deserving punishment.

These adult-sponsored adolescent roles are likely to merely reinforce the obedience and dependence of childhood, rather than allow for the development of the autonomy required in adulthood. Yet adults may be unwilling or unable to revise their views, in part, because revision would undermine their ability to discipline and control.

Since the adult/child dialogue on such matters is again likely to be limited and unproductive, adults may have little influence over the adolescent's initial socialization into independent, autonomous adult roles. Peers (almost by default) become more crucial in defining which behaviors symbolize and/or violate autonomy, and in reinforcing feelings of worth.

In short, a break with past values seems to be virtually assured with entry into adolescence because of the role discontinuities associated with this transition in American society. This break may be exacerbated for cohorts coming of age in periods of social change. The regulative capacities of society may be temporarily undermined during this transition, since previous norms lose relevance. This age transition, then, may signal a period of normlessness - an anomie of age. Because society offers few norms or values to guide or define this transition, the ability to regulate the behavior of these groups is greatly undermined. During this transitional period of normlessness, the adolescent may experiment with "deviant" adaptations in areas where role disjunctions are most acute. Moreover, the power of peers to define standards and to provide acceptable adaptations to an anomie unique to adolescence provides fertile ground for subcultural development. After all, peers seem best able to offer solutions to these problems, while adults who offer "nondeviant" solutions are often seen as insensitive or self-interested.

The strains generated by these discontinuities may be differentially experienced, so that sex and class differences in deviant behavior may be expected. For example, childhood/adult discontinuities in sex roles are greater for females, who may experience normlessness in areas associated with sexual behavior. Further, the inconsistencies between the demands of parents and the demands of peers are likely to be immense in this area. Female deviance, then, frequently involves sex-related crimes.

By contrast, transitions to adult autonomy may be most problematic for males, who may experience as stressful the strains caused by the 
opposition between childhood passivity and adult independence. Hence; the need to unlearn previous values and develop new ones may seem most crucial. For example, it has been suggested that adolescent boys are particularly concerned with these problems of adult autonomy and frequently involve themselves in various forms of deviant behavior (e.g., risk taking, fighting, gambling, joy riding) to affirm their adult status (Matza and Sykes, 1961; Matza, 1964). The limits that adult-sponsored roles impose upon the expression and projection of autonomous images may often lead to the juvenile creation of roles that allow for such expression (Werthman, 1976). Such roles frequently entail some defiance of adults (teachers, parents, police, merchants) as a means to announce or affirm status. Adults, then, come to be used as pawns in this process of affirming worth. This only further limits adult/juvenile dialogue on this topic and adult influence over the development of an emerging autonomy.

Finally, the discontinuity between childhood and adult drug use patterns may be expected to allow for a certain normlessness in this area also. These discontinuities may be experienced as equally frustrating for females and males, since adult drug use patterns are similar. (Indeed, data from some 20 self-report studies indicate that convergence in male and female delinquency rates for drinking are among the closest; Hindelang $e t$ al., 1979; Wise, 1967.)

Adolescent deviance is likely to be greatest at the stress points where discontinuities are greatest. After all, the adolescent's anticipation of future roles and an increase in peer demands may combine to pull the adolescent toward behavior defined as deviant by the standards of previous roles and tolerable by the standards of anticipated roles. Yet no norms define the nature of this transition, nor do norms define the rate at which change should occur. Indeed, when seen in these terms, the defining of adolescent deviance can be understood as dependent upon the pacing of role change, with early role change being characterized by greater adult/juvenile conflict and greater adult labeling of delinquent behavior.

The rate of role change can be expected to vary by class. For example, the assumption of producer roles occurs in the late teens for lower income juveniles, while this transition is often delayed until age 30 for middle and upper income adolescents. Hence, lower income females assume producer (marital/familial) roles at an earlier age than their middle class counterparts; thus, the development of an adult sexual identity may seem especially pressing for the former females during their teens-resulting in "promiscuity" and high rates of illegitimacy. By contrast, middle income females can delay this transition, since marital roles are likewise delayed. If they do become involved in acts regarded as sexually deviant, it may be more likely to be delayed until late adolescence (late teens); hence, the potential for labeling and adult/juvenile conflict is greatly reduced. 
Similarly, lower income males assume producer roles at an earlier age than do their middle class counterparts, so that the former group's need to develop a sense of autonomy (resulting in defiance, truancy, running away) and demonstrate masculinity (e.g., toughness) may seem crucial during the juvenile years. Certainly, self-report studies of institutionalized populations, which are heavily skewed towards lower class juveniles, suggest that these juveniles are more inclined to be involved in behaviors such as first fights, gang fighting, use of force to take money, bullying, destruction of property, and defiance than noninstitutionalized populations, which are greatly skewed towards lower middle class and middle class populations (Short and Nye, 1958; Erickson and Empey, 1965). With this early transition, adult/juvenile conflict and labeling are likely to be greatest, since the legitimacy of such behavior is generally questioned at this point. However, few would question the autonomy of a male who is rapidly approaching age 30 .

\section{CONCLUSIONS}

In this study certain notions about commitment to economic/ achievement values have been called into question. In particular, the notion that values learned in childhood permanently confer worth or generate frustration has been reappraised. It is suggested that the functional differentiation of age strata prevents the use of a single value system or value hierarchy to describe the goals that generate frustration and encourage deviant behavior throughout the life cycle. Social change may cause adolescents and young adults to alter or modify values and value hierarchies acquired during childhood; thus, one is forced to examine conditions that define a sense of failure and encourage frustration for this specific age group. Economic/achievement values hardly seem sufficiently compelling to frustrate an age grade composed of dependent consumers. However, such values can be expected to have an effect among older adolescents for whom employment is imminent, for only at this point do such values begin to provide access to real rather than anticipated rewards and define a design for living.

For younger adolescents, it would seem that the discontinuities between childhood and adult values and roles provide a basis for understanding the values and concerns of youth and ultimately their deviant behavior. These discontinuities cause a break with values acquired during childhood, particularly in the areas of sexual identity, drug use, and autonomy, so that society is limited in terms of its ability to regulate behavior in these areas, for no norms define the ends of action or govern parent/child relationships during this transition. This normlessness or 
anomie of age may lead to adolescent deviation. Furthermore, the power of peers to define standards and to provide acceptable adaptations to an anomie unique to adolescence provides fertile ground for subcultural development. After all, peers seem best able to offer solutions to these problems, while adults offer only conventional solutions, which are often seen as insensitive or self-interested.

Not surprisingly, this transition is characterized by much deviant behavior, particularly in areas where discontinuities are greatest. The labeling of much of this adolescent deviance is also associated with the pace at which this transition occurs, so that early transitions are characterized by much adult/juvenile conflict and labeling. Further, the period of transition may be prolonged under conditions of high unemployment, when delays are experienced in the assumption of autonomous producer roles. Much of the alienation, autonomy assertion, and ultimately deviant behavior which occurs during these young adult years for groups affected by these labor conditions may be understood in terms of this extended period of anomie.

It is suggested that this anomie of age be regarded as a catalyst to delinquent subcultural formation, as it is likely to encourage values and behaviors which seemingly allow adolescents to resolve problems generated by severe discontinuties in certain childhood and adult roles. Moreover, the relevance of this transition for adolescents in terms of confirming worth and providing a design for living assures that values developed in response to these dilemmas will generate a firm, if only temporary, commitment. Finally, to suggest that readiness for this transition is variously perceived by adolescents according to class-linked conditions, which accelerate the aging process for the lower and working class juvenile, is to suggest that certain groups are strained to age at a pace likely to be regarded as premature and therefore problematic.

\section{REFERENCES}

Bacon, M., and Jones, M. (1968). Teenage Drinking, Crowell, New York.

Benedict, R. (1938). Continuities and discontinuities in cultural conditioning. Psychiatry 1(May): 161-167.

Cahalan, D., Cisin, I., and Crossley, H. (1969). American Drinking Practices, College and University Press, New Haven, Conn.

Cahalan, D., and Room, R. (1974). Problem Drinking Among American Men, Rutgers Center of Alcohol Studies, New Brunswick, N.J.

Carey, J., and Mandel, J. (1968). A San Francisco Bay area speed scene. J. Hlth. Soc. Behav. 9: 164-174.

Clausen, J. (1968). Perspectives on childhood socialization. In Clausen, J. Socialization and Society, Little Brown, Boston, pp. 130-181.

Clinard, M. (1964). Anomie and Deviant Behavior, Free Press, New York.

Cloward, R., and Ohlin, L. (1960). Delinquency and Opportunity, Free Press, New York.

Cohen, A. (1955). Delinquent Boys, Free Press, Glencoe, Ill. 
Csikszentmihalyi, M., and Larson, R. (1978). Intrinsic rewards in school crime. Crime Delinquen. 24(July): 322-335.

Davis, F., and Munoz, L. (1968). Heads and freaks: Patterns and meanings of drug use among hippies. J. Hlth. Soc. Behav. 9: 156-163.

Dickinson, G. (1978). Adolescent sex information sources: 1964-1974. Adolescence 13(Winter): 653-658.

Eisenstadt, S. N. (1956). From generation to generation: Age groups and social structure, Free Press, Glencoe, Ill.

Erickson, M., and Empey, L. (1963). Court records, undetected delinquency and decisionmaking. J. Crim. Law, Criminol. Police Sci. 54: 456-467.

Foner, A., and Kertzer, D. (1978). Transitions over the life course: Lessons from age-set societies. Am. J. Sociol. 83: 1081-1104.

Gordon, C. (1976). Development of evaluated role identities. In Inkeles, A., Coleman, J., and Smelser, N. (eds.), Annual Review of Sociology, Vol. 2, Annual Reviews, Palo Alto, Calif., pp. 405-433.

Hindelang, M., Hirschi, T., and Weis, J. (1979). Correlates of delinquency: The illusion of discrepancy between self-report and official measures. Am. Sociol. Rev. 44: 995-1014.

Hornick, J. P. (1978). Premarital sexual attitudes and behavior. Sociol. Quart. 19(Autumn): 534-544.

Kandel, D., Kessler, R., and Marguiles, R. (1978). Antecedents of adolescent initiation into stages of drug use: A developmental analysis. J. Youth Adoles. 7: 13-40.

Kanin, E. J. (1967). Reference groups and sex conduct norm violations. Sociol. Quart. 8: 495-504.

Kohlberg, L., and Gilligan, C. (1971). The adolescent as philosopher: The discovery of the self in a postconventional world. Daedulus 100: 1051-1086.

Kornhauser, R. R. (1978). Social Sources of Delinquency: An Appraisal of Analytic Models, University of Chicago Press, Chicago.

Lerman, P. (1968). Individual values, peer values and subcultural delinquency. Am. Sociol. Rev. 33: 219-235.

Maccoby, E. (1968). The development of moral values and behavior in childhood. In Clausen, J. (ed.), Socialization and Society, Little, Brown, Boston.

Matza, D. (1964). Delinquency and Drift, Wiley, New York.

Matza, D., and Sykes, G. (1961). Juvenile delinquency and subterrranean values. Am. Sociol. Rev. 26: 713-719.

Merton, R. K. (1957). Social Theory and Social Structure, rev. ed., Free Press, Glencoe, Ill.

Neugarten, B., and Peterson, W. A. (1957). A study of the American age grade system. Proceedings 4th Congress Int. Assoc. Gerontol. 3: 497-502.

Ryder, N. (1965). The cohort as a concept in the study of social change. Am. Sociol. Rev. 30: 843-861.

Sapir, E. (1958). Culture, Language and Personality, University of California Press, Berkeley, Calif.

Sexton, P. C. (1969). The Feminized Male: Classroom, White Collars and the Decline of Manliness, Vintage Books, New York.

Short, J., and Nye, I. (1958). Extent of unrecorded delinquency: Tentative conclusions. $J$. Crim. Law Criminol. Police Sci. 49: 296-302.

Simon, W., and Gagnon, J. (1976). The anomie of affluence. Am. J. Sociol. 82: 356-378.

Smart, R., and Fejer, D. (1972). Drug use among adolescents and their parents: Closing the generation gap in mood modification. J. Abnorm. Psychol. 79: 153-160.

Teevan, J. J. (1972). Reference groups and premarital sexual behavior. J. Marr. Fam. 34(May): 283-291.

Werthman, C. (1976). The functions of social definitions in the development of the gang boy's career. In Giallombardo, R. (ed.), Juvenile Delinquency, Wiley, New York, pp. 327-347.

Wise, N. B. (1976). Juvenile delinquency among middle class girls. In Vaz, E. (ed.), MiddleClass Juvenile Delinquency, Harper \& Row, New York, pp. 179-188. 